\title{
Influence of Root Geometry on Bending Stress for Involute Spur Gears
}

\author{
Tufan Gürkan Yılmaz, Fatih Karpat \\ Department of Mechanical Engineering/Uludag University \\ Uludag University Gorukle Campus, Bursa, Turkey \\ tufanyilmaz@uludag.edu.tr; karpat@uludag.edu.tr
}

\begin{abstract}
Involute spur gears are subjected to bending stress on its root and surface stress where the contact occurs during the meshing process. This bending stress affects the bending fatigue life of tooth. The other side, with increasing demand for higher power and torque, the stress level increases. For this reason, designers have begun to investigate non-standard tooth root geometries to decrease it. In this study, different tooth root geometries were designed and analysed for comparing each other in view of bending stress. For this aim, first the mathematical equations of involute and root geometries are programmed in MATLAB, then point cloud of gear tooth were exported to CATIA for generating FEA model, finally the finite element analyses were conducted in ANSYS program for determined gear parameters. Tooth is loaded on highest point single tooth contact (HPSTC). It is seen that elliptical root geometry is more expedient choice for stress reduction. The fully rounded trochoid geometry and circular geometry follow it respectively.
\end{abstract}

Keywords: Involute Spur Gear, Root Geometry, FEA, Elliptical Shape.

\section{Introduction}

Involute spur gears are the most popular power transmission component for various industrial applications such as automotive, machinery, aerospace etc. It has a number of advantages when comparing other gear types for instance; it has easy manufacture process, low sensitivity to assembly errors and constant velocity ratio. Involute spur gear tooth is consisted of two blending different type of curves (involute and root). Involute curve called as working portion, contact with mating gear tooth during mesh cycle while root curve called as non-working portion has no effect on meshing process. The form of this curve is directly related with load carrying capacity of gear. With increasing demand for higher moment and forces, the gear designers have begun to search non-standard tooth geometries. Among these, asymmetric tooth profile stands out first. Kapelevich [1] put forward the asymmetric tooth geometry and design principles. The limits of asymmetric concept were determined. Karpat et al. [2] investigated effect of changing pressure angle on drive side of gear on bending stress with FEA. When increasing pressure angle $20^{\circ}$ to $40^{\circ}$ on drive side, the stress reduces $35 \%$ approximately. On the other hand, it reduces contact ratio and effects meshing process negatively. Another non-standard method is using asymmetric trochoid profile. Y1lmaz et al. [3] studied on involute internal spur gear generated with rack cutter has different tip radius value on its sides. Thus extra larger tip radius could be designed on a side. As the results of finite element analyses, the maximum stress reduced approximately $16 \%$ when tip radius was increased from $0,2 \times \mathrm{m}$ to $0,5 \times \mathrm{m}$. Y1lmaz et al. [4] conducted FEA studies to find out the effects of asymmetric trochoid on thin rimmed spur gears. According to results, stress level decreases $12 \%$ averagely, when tip radius was increased standard value to $0,58 \times \mathrm{m}$. With these methods, the gears could be manufactured with traditional standard cutters. The other method is generating analytical (circular) and synthetic curves (cubic splines, hermite etc.) between involute curve and dedendum circle to blend them with tangent or curvature continuity. Spitas et al. [5] offered circular curve to decrease bending stress as an analytical curve. The finite and boundary element methods were used to understand the effect of this type root curve. Especially for spur gear with low teeth number $(\mathrm{z}<17)$, the using circular fillet has lower stress level than fully rounded trochoid one. Zou et al. [6] designed a novel type root curve and conducted stress and fatigue analyses for different loads. An algorithm was used to reach optimum curve. This proposed curve is superior to circular and trochoid curves in view of load carrying capacity and service life. Fuentes et al. [7] proposed hermite curve as spur gear's root profile. They changed the tangent weight of hermite curve at start and finish points and specified its effect on bending stress. They reached a conclusion that if the tangent weight decreases the load carrying capacity is enhanced.

In this study, the elliptical curve was used as root profile and compared with circular and trochoid ones in view of bending stress. First the equations are derived for involute and root curves. A MATLAB code was generated to specify 
coordinates of tooth points. Then these points were exported to CATIA. 2D models were prepared for finite element analyses conducted in ANSYS. According to results, elliptical curve has the lowest stress value when comparing circular and trochoid curves.

\section{Equations of Spur Gear Tooth}

\subsection{Equations of Involute and Trochoid Curve}

In this study, equations of involute and trochoid curves were derived by using Litvin's approach based on traditional manufacturing kinematics [8]. Cutter's equations were obtained from previous study[4], then the open equations of involute spur gear tooth were derived. $S_{n}\left(X_{n}, Y_{n}\right)$ is the coordinate system of rack cutter. $S_{1}\left(X_{1}, Y_{1}\right)$ is the coordinate system of involute spur gear.

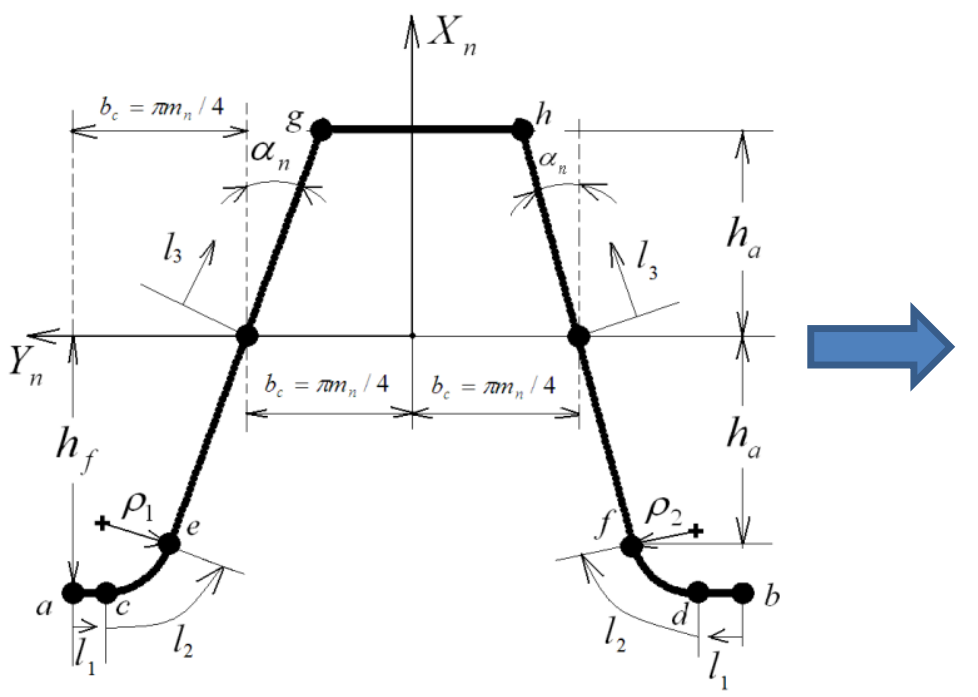

(a)

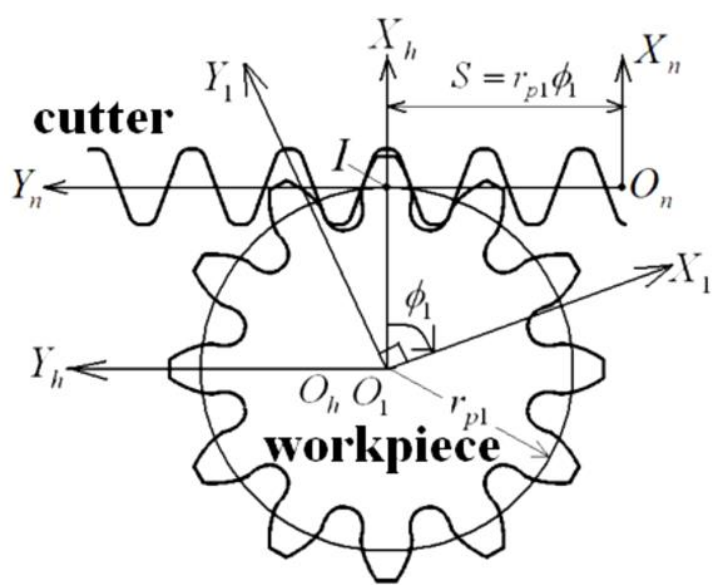

(b)

Fig. 1: a) Geometry of rack cutter and relation b) Relation between cutter and workpiece.

In Figure 1a, there are six region to generate involute gear tooth. ac and bd regions constitute bottom land, ce and df regions constitute trochoid curve, eg and fh regions constitute involute curve of spur gear tooth. In our study the ac and bd regions are not existed since the fully rounded rack cutter is used.

With using the regions equations, coordinate transformation matrix between workpiece and cutter and the gearing theory from previous study[4], the equations of involute and trochoid curves were obtained in following equations;

Trochoid curve

$$
\begin{aligned}
x_{1}^{c e}=\left(-h_{f}\right. & \left.+\rho_{1}-\rho_{1} \cos l_{2}\right) \cos \emptyset_{1}-\left(b_{c}+h_{f} \tan \alpha_{n}-\rho_{1} \tan \alpha_{n}+\rho_{1} \sec \alpha_{n}-\rho_{1} \sin \left(l_{2}\right)\right) \sin \emptyset_{1} \\
& +r_{p 1} \cos \emptyset_{1}+r_{p 1} \emptyset_{1} \sin \emptyset_{1}
\end{aligned}
$$


Involute curve

$$
\begin{gathered}
x_{1}^{e g}=l_{3} \cos \alpha_{n} \cos \emptyset_{1}-\left(b_{c}-l_{3} \sin \alpha_{n}\right) \sin \emptyset_{1}+r_{p 1} \cos \emptyset_{1}+r_{0} \emptyset_{1} \sin \emptyset_{1} \\
y_{1}^{e g}=l_{3} \cos \alpha_{n} \sin \emptyset_{1}+\left(b_{c}-l_{3} \sin \alpha_{n}\right) \cos \emptyset_{1}+r_{p 1} \sin \emptyset_{1}-r_{p 1} \emptyset_{1} \cos \emptyset_{1} \\
\emptyset_{1}=\frac{-l_{e} \cos \alpha_{n}+b_{c}-l_{e} \sin \alpha_{n}}{r_{p 1} \tan \alpha_{n}}
\end{gathered}
$$

Where; $h_{f}$ is dedendum, $h_{a}$ is addendum, $b_{c}$ is half of tooth thickness at pitch circle, $\rho_{1}$ and $\rho_{2}$ is tip radius on sides, $\alpha_{n}$ is pressure angle, $r_{p 1}$ is pitch circle radius, $l_{2}$ and $l_{3}$ are design variables of trochoid and involute curve respectively, $\varnothing_{1}$ is roll angle.

\subsection{Equations of Elliptical Curve}

In this section, elliptical curves were generated as root curve to blend involute curve and dedendum circle. The differences between elliptical curves result from starting point of curve. This starting point is on involute curve and has to be under the limit circle to avoid interference condition. Besides, elliptical curve has to ensure tangent continuity (G1) when joining involute and dedendum circle to avoid stress intensity. To meet these conditions, the following equations have to be ensured. In Figure 2 the geometry of elliptical curve is illustrated.

$$
\begin{gathered}
x_{1}^{e g}=x_{1}^{\text {elliptical }}=x_{A} \\
y_{1}^{e g}=y_{1}^{\text {elliptical }}=y_{A} \\
\frac{d y_{1}^{e g}}{d x_{1}^{e g}}\left|\left(x=x_{A}\right)=\frac{d y_{1}^{\text {elliptical }}}{d x_{1}^{\text {elliptical }}}\right|\left(x=x_{A}\right) \\
x_{1}^{\text {elliptical }}=x_{1}^{\text {dedendum }}=x_{C} \\
y_{1}^{\text {elliptical }}=y_{1}^{\text {dedendum }}=y_{C} \\
\frac{d y_{1}^{\text {elliptical }}}{d x_{1}^{\text {elliptical }}}\left|\left(x=x_{C}\right)=\frac{d y_{1}^{\text {dedendum }}}{d x_{1}^{\text {dedendum }}}\right|\left(x=x_{C}\right)
\end{gathered}
$$



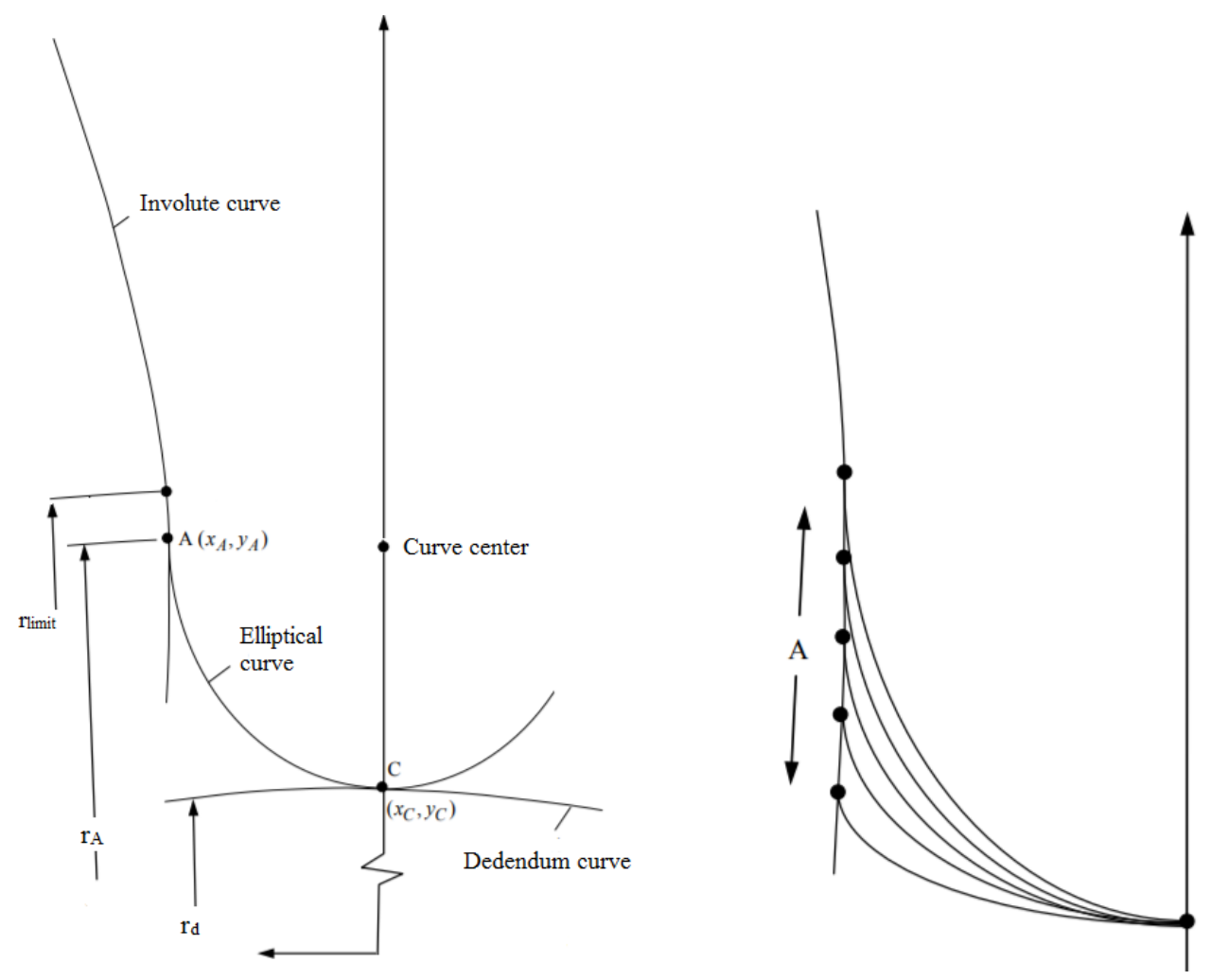

Fig. 2: Generating of elliptical curve with different starting point.

The mathematical expression of elliptical curve is presented in the following equations:

$$
y_{1}^{\text {elliptical }}=\sqrt{\frac{b^{2}\left(a^{2}-\left(x_{1}^{\text {elliptical }}\right)^{2}\right)}{a^{2}}}
$$

Where $\mathrm{a}$ and $\mathrm{b}$ are semi-minor and semi-major axis of ellipse, $\mathrm{r}_{\text {lim }}$ is the limit diameter of gear which is related with mating gear parameters. With solving Eq. (7-12), the "a" and "b" could be determined. Please note that, when "a" and "b" are equal, then the circular curve is generated.

The equations of involute, trochoid and elliptical curves were programmed in MATLAB, and tooth profiles are generated for finite element analyses in CATIA. In Figure 3 the design phases and profile of root curves were illustrated. 
$\begin{array}{llll}X & Y & Z\end{array}$

$40.264932 \quad 4.757343 \quad 0.000000$ $49.268006 \quad 4.732676 \quad 0.000036$ $40.271396 \quad 4.708050 \quad 0.000000$ $40.275102 \quad 4.683467 \quad 0.000000$ $40.279122 \quad 4.658932 \quad 0.000090$ $40.283457 \quad 4.634446 \quad 0.000000$ 49.293068 4.585637 0.000030 40.2983444 .5613200 .000000 $40.303932 \quad 4.537066 \quad 0.000000$ $18.309832 \quad 4.5128770 .000030$ $40.316043 \quad 4.488758 \quad 0.000000$ $48.322566 \quad 4.4547100 .000030$ $40.3294004 .440737 \quad 0.000000$ 48.336543 4.416843 $40.343997 \quad 4.3939290 .00000$ $40.3517594,369300 \quad 0.000000$ $40.359830 \quad 4.345658 \quad 0.000000$

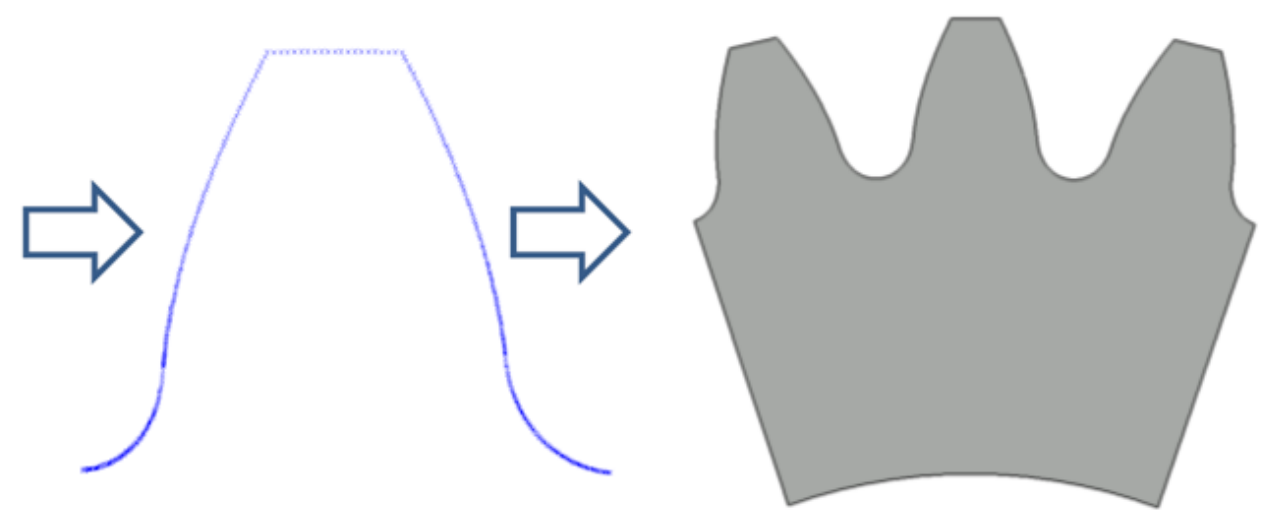

(a)

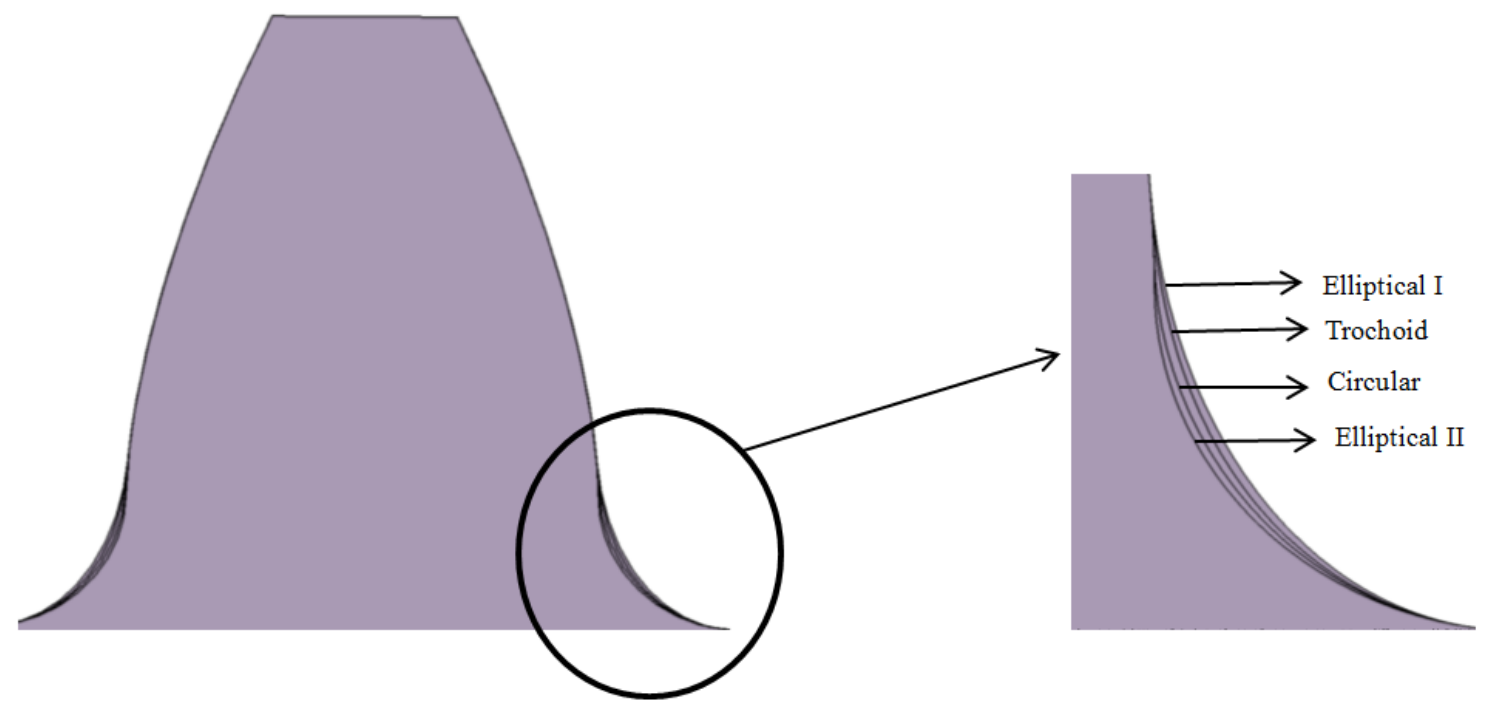

(b)

Fig. 3: a) Design phases of gear tooth b) Detail views of root curves.

\section{Finite Element Analysis}

In this study, to evaluate effects of shape of root curve on bending stress for spur gear; finite element analyses were conducted in ANSYS for different root shapes. The gear parameters used in analyses are presented in Table 1.

Table 1: Design parameters of gears.

\begin{tabular}{|c|c|c|c|c|}
\hline Gear parameters & Elliptical I & Fully Rounded Trochoid & Circular & Elliptical II \\
\hline Module-m (mm) & 4 & 4 & 4 & 4 \\
\hline Pressure angle- $\alpha_{n}\left({ }^{\circ}\right)$ & 20 & 20 & 20 & 20 \\
\hline Dedendum- $\mathrm{h}_{\mathrm{f}}(\times \mathrm{m})$ & 1,25 & 1,25 & 1,25 & 1,25 \\
\hline Upper radius of root curve- $\mathrm{r}_{\mathrm{A}}(\mathrm{mm})$ & 53,335 & 53,09 & 52,939 & 52,779 \\
\hline Lower radius of root curve- $\mathrm{r}_{\mathrm{d}}(\mathrm{mm})$ & 51 & 51 & 51 & 51 \\
\hline
\end{tabular}


3 teeth 2D model is used for analysis. Normal force $(100 \mathrm{~N})$ is applied at highest point of single tooth contact (HPSTC). Fixed support is given on lateral sides and shaft hole. Boundary condition and mesh display are illustrated in Figure 4.

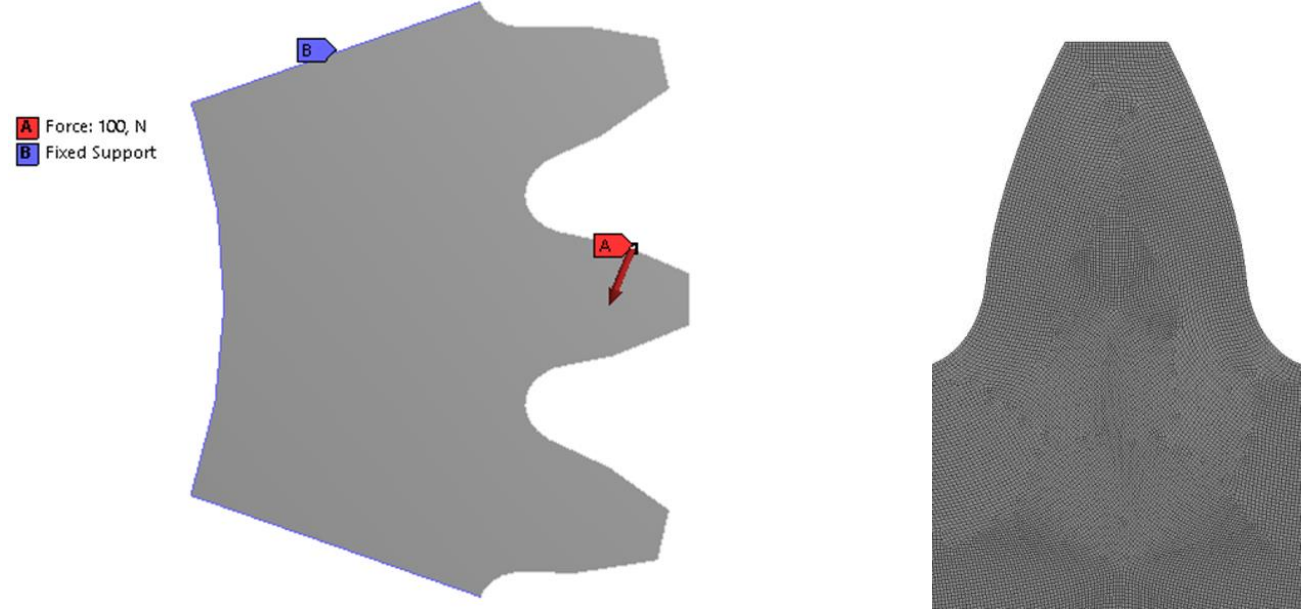

Fig. 4: Mesh structure and boundary condition.

In analysis; quadrilateral element type is used with 0.1 mesh size. Model has approximately 66670 elements and has 201209 nodes. In Figure 5, the results of case studies are presented.
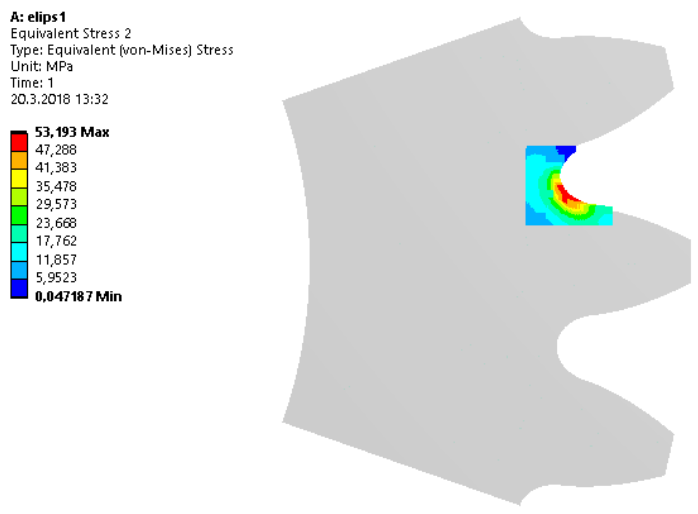

(a)

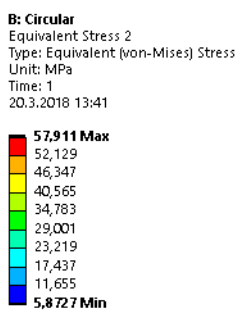

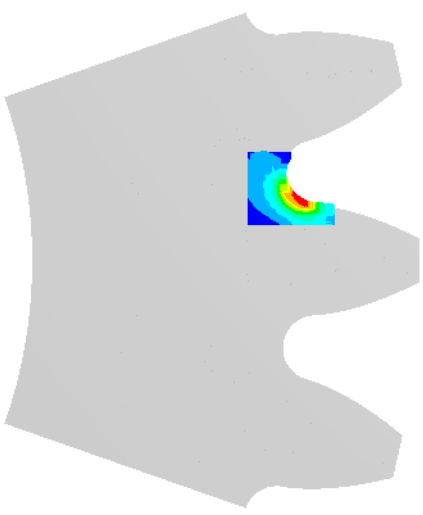

(c)
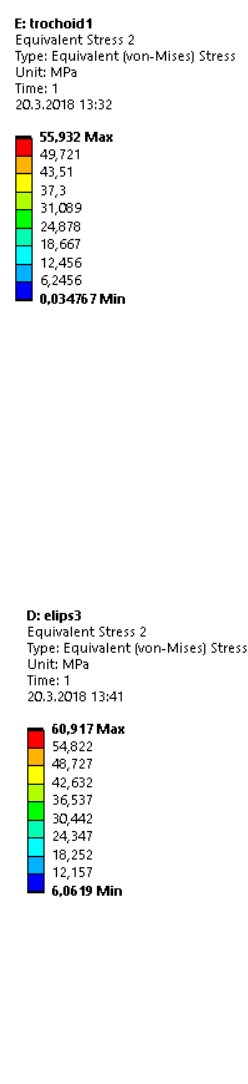

Fig. 5: Results of Case studies a) Elliptical I b) Trochoid c) Circular d) Elliptical II.

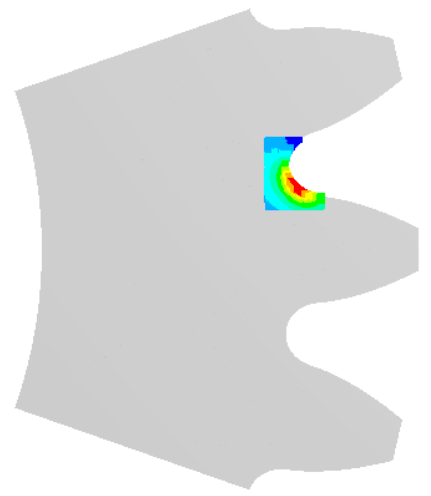

(b)

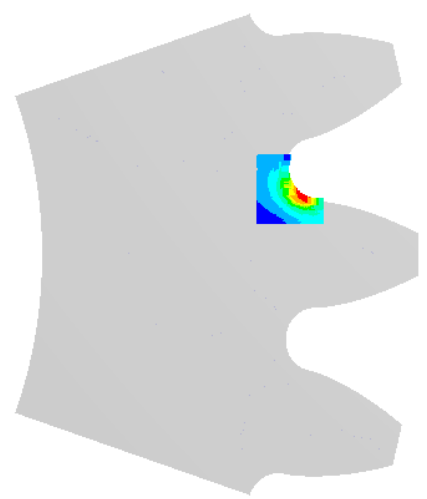

(d) 
When comparing the results, the Ellitical I is the best choise in view of bending stress. Hovewer; It is not true statement that elliptical curve is always best in general. Since Elliptical II has highest bending stress value among the curves. Circular root shape is not brillant choice to reduce bending stress according to results. Actually the upper radius of root curve is significant parameter as it affects the stress concentration. In Figure 6 the relation between stress and upper radius of root curve is presented.

It is clearly seen from Figure 6 that, when the upper radius of root curve is increased, the bending stress value decreases. Elliptical I which has biggest upper radius value has approximetly 5\% lower bending stress value than full rounded trochoid.

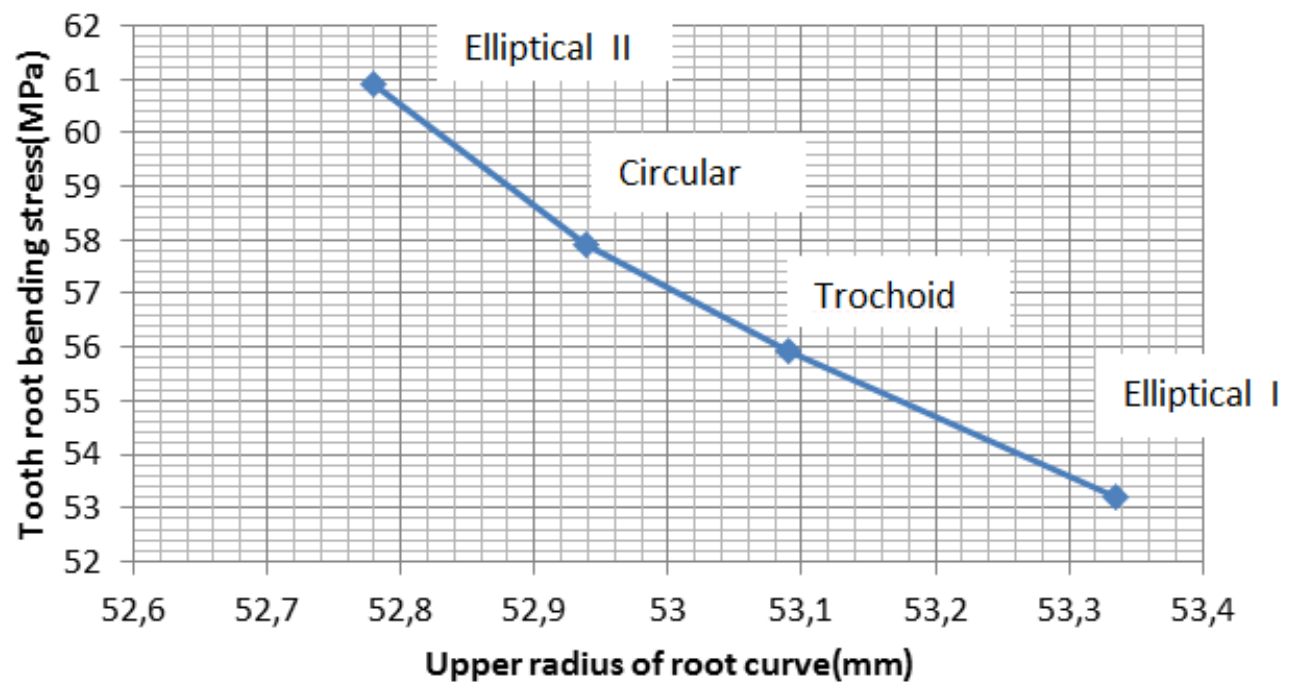

Fig. 6: Bending stress with changing upper radius of curve.

\section{Conclusion}

In this study, first the mathematical equations of involute, trochoid and elliptical curves were expressed. With programming equations, the points of gear tooth were obtained. The points were exported to CAD program for generating 2D model of gear. To understand the effect of different shapes on bending stress, finite element analyses are conducted for determined gear parameters. According to results, the elliptical curve with higher upper radius value could be used to decrease bending stress. The upper radius value is one of the most crucial parameter in view of bending stress. For $\mathrm{z}=28$, circular curve has nearly $5 \%$ higher bending stress than fully rounded trochoid curve. For this reason, it not a good alternative for bending stress reduction.

\section{References}

[1] A. Kapelevich, "Geometry and design of involute spur gears with asymmetric teeth," Mech. Mach. Theory, vol. 35, no. 1 , pp. 117-130, 2000.

[2] F. Karpat, K. Cavdar, F.C. Babal1k, "Computer aided analysis of involute spur gears with asymmetric teeth," in Proceedings of International Conference on Gears, Garching, Germany, VDI BERICHTE, pp. 145-163, 2005.

[3] T. G. Y1lmaz, O. Dogan, C. Yuce, F. Karpat, "Improvement of the loading capacity of internal spur gears with using asymmetric trochoid profile," in ASME International Mechanical Engineering Conference \&Exhibtion, Tampa, USA, 2017.

[4] T. G. Y1lmaz, O. Dogan, F. Karpat, "Stress analysis of thin rimmed spur gears with asymmetric trochoid," in MCM Congress International Conference on Mechanics and Industrial Engineering, Rome, Italy, 2017.

[5] C. Spitas and V. Spitas, "A FEM study of the bending strength of circular fillet gear teeth compared to trochoidal fillets produced with enlarged cutter tip radius," Mech. Based Des. Struc., vol. 35, no. 1, pp. 59-73, 2007.

[6] T. Zou, M. Shaker, J. Angeles, A. Morozov, "An innovative tooth root profile for spur gears and its effect on service life," Meccanica, vol. 52, pp. 1825-1841. 
[7] A. Fuentes-Aznar, P. Iglesias-Victoria, S. Eisele, I. Gonzalez-Perez, "Fillet geometry modeling for nongenerated gear tooth surface," in Proceedings of International Conference on Power Transmission, Chongqing, P.R. China, 2017, pp. 431-436.

[8] F. L. Litvin and A. Fuentes, Gear Geometry and Applied Theory. Cambridge, Cambridge University Press, 2004. 